\title{
Secondary Filtration of Closed Loop in DC Locomotive
}

\author{
Dr. K Muthukumar1, V. Nagendra Kumar² \\ 1Professor, 2PG Safety Student \\ 1,2Department of Mechanical Engineering, Bannari Amman Institute of Technology, \\ 1,2Sathyamangalam Erode, Tamil Nadu, India
}

\begin{abstract}
How to cite this paper: $\mathrm{Dr} . \mathrm{K}$ Muthukumar | V. Nagendra Kumar "Secondary Filtration of Closed Loop in DC Locomotive" Published in International Journal of Trend in Scientific Research and Development (ijtsrd), ISSN: 24566470, Volume-3 | Issue-3, April 2019, pp.1106-1119, URL: https://www.ijtsrd.c om/papers/ijtsrd23 220.pdf

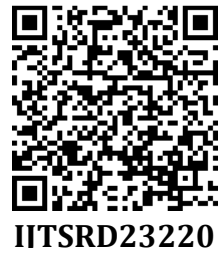

Copyright (C) 2019 by author(s) and International Journal of Trend in Scientific Research and Development Journal. This is an Open Access article distributed under the terms of the Creative Commons

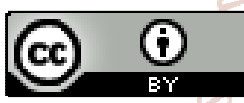
Attribution License (CC BY 4.0) (http://creativecommons.org/licenses/ by $/ 4.0$ )

\section{INTRODUCTION}

In Industrial and mobile applications at factories all over the world, one can often see hydraulic circuits that don't include proper fluid filtration, or include it as an afterthought. Good filtration needs to be an integral part of the hydraulic circuit to ensure the long life proper orientation of the pumps, valves and motors. The functionality of oils suffers when contaminated with particles. Filtration can play a key role in ensuring that hydraulic and lubricating systems are running effectively. Fuels, hydraulic and lubricating oil are used in different industries. Different sources and processes produce this contamination. Even in a closed system, the oil contains impurities due to sludge, abrasives and contamination of the tubes, containers and seals. In an open system, the operating liquid can be contaminated by the same things as well as dirt and dust from outside. To avoid damage in engines with operating liquids, the particle contamination should be monitored to change the oil on time or contamination should be prevented through filtration. Oil of any kind is no longer a cheap commodity, so cleaning and reclaiming oil from industrial systems, where it has become contaminated, is an important and necessary process, as well as a profitable environmental investment. Of all of the utility applications of filtration, the filtration of hydraulic systems is probably the most important, because of the critical need to keep hydraulic fluids free of solid contaminants, and because of the very wide application of hydraulic systems themselves.
The general problem of separating solids from liquids may be solved by a wide variety of operations depending upon the character of the solid and the proportion of solid to liquid in the mixture to be separated. When the amount of solid is relatively small as compared to the liquid, the process is usually called filtration. Filtration is the removal of solid particles from a fluid by passing the fluid through the filtering medium or the septum, on which the solids are deposited. Commercial or Industrial filtrations cover a wide range of applications. The suspended solid particles can be very fine (in micrometre range) or much larger, very rigid or plastic particles, spherical or very irregular in shape, aggregates of particles or individual particles.

\section{Protection of Hydraulic Components}

Fluid power circuits are designed in all shapes and sizes, both simple and complex in design, and they all need protection from damaging contamination. Abrasive particles enter the system and, if unfiltered damage sensitive components like pumps, valves and motors. It is the job of the hydraulic filter to remove these particles from oil flow to help prevent premature component wear and system failure. As the sophistication of hydraulic system increases, the need for reliable filtration protection becomes ever more critical. 


\section{Closed Loop Filtration}

One very effective way of ensuring thorough fluid conditioning is with a dedicated off-line circulation loop, or "kidney" loop or Closed loop filtration. This system uses a separate circulation pump that runs continuously, circulating and conditioning the fluid. Multiple stages and types of filters can be included in the circuit.

\section{OIL CONTAMINATION}

It is highly important to use clean oil for hydraulic systems. Oil that contains contaminants can shorten the life of a component. The primary cause of hydraulic system failure is contamination. At least 75 percent of all hydraulic systems fail due to contaminated or aging hydraulic fluid.1 Contamination causes aging/degradation of fluids and hydraulic systems failure for numerous reasons. In addition to increasing internal leakage (which lowers the efficiency of pumps, motors and cylinders), contamination decreases the ability of valves to control flow and pressure, thus wasting horsepower and generating excess heat. Furthermore, it causes parts to stick due to sludge or silting, or seize when large amounts of contaminants accumulate in the clearances. Sources of contamination can include the manufacturing process, hydraulic fluids, environmental exposure, system wear and servicing. Contamination of a fluid can have various sources and modes. Contamination could be solids and/or liquids.

\subsection{Contaminants}

While hydraulic system contaminants can be either solid particles or liquids, water is the most common. Solid particles contaminate by chemically reacting with the fluid, or fouling the system through accumulation. The presence of both water and particulate contamination can lead to the formation of insoluble precipitates, and viscous sludge and gels. These materials induce excessive stress on system components especially pumps and can clog orifices, nozzles, and jets.

\subsubsection{Water}

The behaviour of water as a contaminant varies from system to system. Water can form an emulsion with the fluid, or it may be partially immiscible, floating on the surface or settling to the bottom of the fluid depending on the relative density. The presence of water ultimately results in corrosion of the system components and resultant contamination of the fluid by corrosion products. Water ingress may be caused by design flaws, service environment, maintenance activities, internal generation and various methods of fluid servicing. Water is a poor lubricant, and significant concentrations of water in hydraulic fluids can decrease their viscosity and load-carrying ability, as well as hydrodynamic-film thickness. This can lead to greater surface-to-surface contact at sliding and rolling dynamic clearances, and hence, increased component wear. Hydrolysis the alteration or decomposition of a chemical substance due to the presence of water is another potential problem in hydraulic fluids. The acidic compounds that may form during hydrolysis can react with materials of the hydraulic-system components, leading to corrosion and insoluble corrosion products.

\subsubsection{Oxidation}

Oxidation of the fluid base stock is a primary chemicaldegradation process in many hydraulic fluids. The oxidation process proceeds through a series of chemical chain reactions and is self-propagating with the intermediate, reactive chemical species regenerating themselves during the process. The result is the formation of oxygenated compounds and, eventually, high-molecular-weight polymeric compounds. All of these compounds often are insoluble; they settle out of the fluid as gums, resins, or sludge.

\subsection{Contamination effects}

The effects of contamination typically begin with the hydraulic fluid, then are carried into the system, and can continuously worsen in a closed or sealed system. Additionally, contaminants such as water, other liquids, and even required chemicals (additives) can cause solids or slime to accumulate in the system, gradually reducing the performance of valves and other tight tolerance components. These vicious cycles will continue to quietly rob a hydraulic system's performance, long after decontamination measures are taken. Solid particles cause damage according to their size. High concentrations of small particles form silt which erodes the interior mating surfaces of valves, rendering them inoperable. Contaminating solid particles that are equal in size to the clearance between two moving surfaces can cause both jamming and wear. Larger contaminating particles block ports and orifices, and can cause transient malfunction (coincident jamming) when trapped by a mechanism moving from one position to the next (for example, a particle trapped between a poppet and its seat prevents the closing of a relief valve). The main result of contamination is system malfunction. This is broadly classified into three categories as Degradation (gradual changes over time in pump flow rates, valve leakage and wear of cylinder barrels causing cylinder speed decline, etc.), Transient (intermittent failures) and Catastrophic (complete failure of a system or component)

\section{New Hydraulic Fluid}

Adding new fluid can be a source; even though it is fresh from the drum, new hydraulic fluid isn't clean. Oil out of shipping containers is usually contaminated to a level above what is acceptable for most hydraulic systems; typically new fluid has a cleanliness about the same as ISO code $23 / 21 / 19$, and water content 200 to $300 \mathrm{ppm}$. Never assume your oil is clean until it is filtered. One very effective way ensuring thorough fluid conditioning is with a dedicated offline circulation loop or "kidney" loop filtration

\subsubsection{Built-In}

Built-in contamination, also called primary contamination, is caused during the manufacture, assembly and testing of hydraulic components. Metal filings, small burrs, pieces of Teflon tape, sand and other contaminants are routinely found in initial clean up filtration of newly manufactured systems.

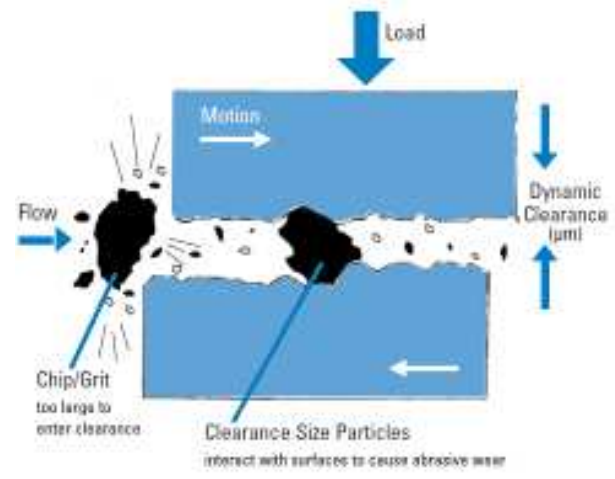

Figure 3.1 Wear due to Contamination 
In the fig 3.1, an illustration for wear due to contamination is shown. If the contamination particle size is greater than the clearance, then the wear occurs

\section{Ingressed}

Ingressed or external contamination comes from the environment surrounding the system. Dirt can enter the hydraulic fluid supply through leaking seals, reservoir breather caps, and worn cylinder rod seals. Ingressed moisture, particularly, can cause long-term problems. As a hot system cools at night, cool moisture-laden air can be drawn into the reservoir; as the air condenses, water is released into the reservoir. Water in excess of $0.5 \%$ by volume in a hydrocarbon-based fluid accelerates the formation of acids, sludge and oxidation that can attack internal components, cause rust, and adversely affect lubrication properties. The severity of ingression and type of contaminant are dictated by the applications and environment.

\section{In-Operation}

The major source of contamination are the pump and actuators, the hydraulic cylinder, or the hydraulic motor. Wear-generated contaminants are a hazard during normal hydraulic system operation. The circuit actually generates additional particles as the fluid comes into contact with the precision machined surfaces of valves, motors and pumps. Contaminant levels can keep doubling with every new particle generated. The result can be catastrophic if these contaminants are not properly filtered out of the system.

\section{Particulate Removal}

Particulate removal is usually done with mechanical filters. A well designed reservoir that allows settling will also help in keeping particulates out of the mainstream fluid. For ferrous particulates and rust, reservoir magnets or strainer band magnets can also be used. Other methods such as centrifuging or electrostatic filtration units can also be used, particularly in continuous batch processing and fluid reclamation.

\section{Removal of Silt}

Silt, defined as very fine particulate under $5 \mu \mathrm{m}$ in size, requires very fine filtration or "oil polishing."

\section{Air Removal}

Getting air out of the system is best done by adding 100 mesh screen in the reservoir, approximately $30^{\circ}$ from horizontal to coalesce entrained air and allow larger bubbles to rise to the surface when reservoir velocities are low.

\section{Water Removal}

A number of techniques exist to prevent water or moisture ingression or to remove water once it is present in a hydraulic or lube oil system. The best choice of technique for removal is dependent on the whether or not the water exists as a separate phase (dissolved or free), and also on the quantity of water present. For example, the presence of water or moisture can be reduced or prevented from entering a fluid reservoir through the use of absorptive breathers or active venting systems. However once free water is present in small quantities, water absorbing filters or active venting systems usually provide adequate removal means. For large quantities of water, vacuum dehydration, coalescence, and centrifuges are appropriate techniques for its removal. However, as each of these techniques operates on different principles, they have various levels of water removal effectiveness. The chart below provides comparative information on these techniques and their relative effectiveness. Care should be taken to apply the best technique to a given situation and its demands for water removal.

\section{CONTAMINATION STANDARDS Oil Cleanliness Standards}

It is widely accepted that particle contamination reduces the service life of hydraulic components. Fact is, some level of particle contamination is always present in hydraulic fluid, even in new fluid. The level of contamination or conversely, the level of cleanliness considered acceptable, depends on the type of hydraulic system. There are different standards of measurement used such as ISO, SAE and NAS of which International Organization for Standardization (ISO) is more common and widely utilized.

\section{ISO Cleanliness Standards}

The International Organization for Standardization (ISO) has developed a cleanliness code that is the primary piece of data reviewed on most industrial oil analysis reports. The value of this code can help determine the overall cleanliness of the monitored system. Often times, an end user will establish a target value to achieve, thus offering a level of confidence so long as the used oil sample meets this established target.

ISO 4406-1999 is the reporting standard for fluid cleanliness. According to this standard, a code number is assigned to particle count values derived at three different micron levels: greater than 4 microns, greater than 6 microns and greater than 14 microns. The ISO code is assigned based upon Table 4.1.

\begin{tabular}{|c|c|c|}
\hline \multirow{2}{*}{ ISO code number } & \multicolumn{2}{|c|}{ Number of particles per $\mathrm{ml}$} \\
\hline & More than & Up to and including \\
\hline 22 & 20000 & 40000 \\
\hline $04 / 021$ & 10000 & 20000 \\
\hline 20 & 5000 & 10000 \\
\hline 19 & 2500 & 5000 \\
\hline 18 & 1300 & 2500 \\
\hline$-\quad 17$ & 640 & 1300 \\
\hline 16 & 320 & 640 \\
\hline 15 & 160 & 320 \\
\hline 14 & 80 & 160 \\
\hline 13 & 40 & 80 \\
\hline 12 & 20 & 40 \\
\hline 11 & 10 & 20 \\
\hline 10 & 5 & 10 \\
\hline 09 & 2.5 & 5 \\
\hline 08 & 1.3 & 2.5 \\
\hline 07 & 0.64 & 1.3 \\
\hline
\end{tabular}

However, without seeing the raw data, the only thing the ISO code can positively identify is whether a sample has achieved the desired target value. The ISO code does nothing to help determine any type of real trend information unless the value of the raw data at the given micron levels changes enough to raise or lower the ISO code.

\section{National Aerospace Standard}

NAS stands for 'National Aerospace Standard of America. NAS 1638 is the standard for oil cleanliness which indicates the number of microscopic particles of different size say 2-5, 5-15, 15-25, 25-50, 50-100 and above 100 micron present in $100 \mathrm{ml}$ oil sample. NAS classes are described in the Table 4.2 
International Journal of Trend in Scientific Research and Development (IJTSRD) @ www.ijtsrd.com eISSN: 2456-6470

Table 4.2 NAS Classes for cleanliness

\begin{tabular}{|c|c|c|c|c|c|c|}
\hline \multicolumn{2}{|c|}{$\begin{array}{c}\text { Size } \\
\text { Range }\end{array}$} & $\begin{array}{l}\text { 5-15 } \\
\mu \mathrm{m}\end{array}$ & $\begin{array}{l}15- \\
25 \\
\text { um }\end{array}$ & $\begin{array}{c}25- \\
50 \mu \mathrm{m}\end{array}$ & $\begin{array}{c}50- \\
100 \mu \mathrm{m}\end{array}$ & $\begin{array}{c}>100 \\
\mu \mathrm{m}\end{array}$ \\
\hline \multirow{14}{*}{ 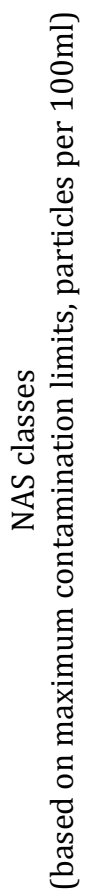 } & 00 & 125 & 22 & 4 & 1 & 0 \\
\hline & 0 & 250 & 44 & 8 & 2 & 0 \\
\hline & 1 & 500 & 89 & 16 & 3 & 1 \\
\hline & 2 & 1000 & 178 & 32 & 6 & 1 \\
\hline & 3 & 2000 & 356 & 63 & 11 & 2 \\
\hline & 4 & 4000 & 712 & 126 & 22 & 4 \\
\hline & 5 & 8000 & 1425 & 253 & 45 & 8 \\
\hline & 6 & $\begin{array}{c}16 \\
000 \\
\end{array}$ & 2850 & 506 & 90 & 16 \\
\hline & 7 & $\begin{array}{c}32 \\
000 \\
\end{array}$ & 5700 & 1012 & 180 & 32 \\
\hline & 8 & $\begin{array}{c}64 \\
000 \\
\end{array}$ & $\begin{array}{c}11 \\
400 \\
\end{array}$ & 2025 & 360 & 64 \\
\hline & 9 & $\begin{array}{l}128 \\
000\end{array}$ & $\begin{array}{c}22 \\
800\end{array}$ & 4050 & 720 & 128 \\
\hline & 10 & $\begin{array}{l}256 \\
000 \\
\end{array}$ & $\begin{array}{c}45 \\
600 \\
\end{array}$ & 8100 & 1440 & 256 \\
\hline & 11 & $\begin{array}{l}512 \\
000 \\
\end{array}$ & $\begin{array}{c}91 \\
000 \\
\end{array}$ & 16200 & 2880 & 512 \\
\hline & 12 & $\begin{array}{c}102 \\
4000\end{array}$ & $\begin{array}{l}182 \\
400\end{array}$ & 32400 & 5760 & 1024 \\
\hline
\end{tabular}

The NAS values of measurement are highly important as they, to a large extent, determine the type of fluid and filter that are to be used. Different hydraulic systems work under different conditions and each system has different safe contamination levels, hence NAS values are utilized to determine the safety levels and the type of filter that needs to be employed for safe working of the system.

\section{SAE Cleanliness Standards}

The Society of Automotive Engineers aerospace standard AS4059 defines cleanliness classes for particulate contamination of hydraulic fluids and includes methods of reporting related data. The contamination classes selected are based on the widely accepted older NAS cleanliness classes. The table 4.3 shows the number of particles $/ 100 \mathrm{~mL}$ fluid based on differential particle count.

SAE (Cleanliness Classes for Differential Counts), (Particles per $100 \mathrm{ml}$ )

Table 4.3 SAE Codes for cleanliness

\begin{tabular}{|c|c|c|c|c|c|}
\hline Code & $\begin{array}{c}6-14 \\
\text { um }\end{array}$ & $\begin{array}{c}14-21 \\
\mu m\end{array}$ & $\begin{array}{c}21-38 \\
\mu m\end{array}$ & $\begin{array}{c}38-70 \\
\mu m\end{array}$ & $\begin{array}{c}>70 \\
\mu m\end{array}$ \\
\hline 0 & 125 & 22 & 4 & 1 & 0 \\
\hline 0 & 250 & 44 & 8 & 2 & 0 \\
\hline 1 & 500 & 89 & 16 & 3 & 1 \\
\hline 2 & 1000 & 178 & 32 & 6 & 1 \\
\hline 3 & 2000 & 356 & 63 & 11 & 2 \\
\hline 4 & 4000 & 712 & 126 & 22 & 4 \\
\hline 5 & 8000 & 1425 & 253 & 45 & 8 \\
\hline 6 & 16000 & 2850 & 506 & 90 & 16 \\
\hline 7 & 32000 & 5700 & 1012 & 190 & 32 \\
\hline 8 & 64000 & 11400 & 2025 & 360 & 64 \\
\hline 9 & 128000 & 22800 & 4050 & 720 & 128 \\
\hline 10 & 256000 & 45600 & 8100 & 1440 & 256 \\
\hline
\end{tabular}

\section{Comparison Chart for ISO, NAS and SAE}

Comparison between the various standards of contamination can be made based on the size and number of contaminants measured. From the Table 4.4 the equivalent values of cleanliness in various standards can be known

Table 4.4 Comparison between ISO, NAS and SAE

\begin{tabular}{|c|c|c|}
\hline ISO & NAS & SAE \\
\hline $13 / 11 / 08$ & 2 & \\
\hline $14 / 12 / 09$ & 3 & 0 \\
\hline $15 / 13 / 10$ & 4 & 1 \\
\hline $16 / 14 / 11$ & 5 & 2 \\
\hline $17 / 15 / 10$ & 6 & 3 \\
\hline $18 / 16 / 13$ & 7 & 4 \\
\hline $19 / 17 / 14$ & 8 & 5 \\
\hline $20 / 18 / 15$ & 9 & 6 \\
\hline $21 / 19 / 13$ & 10 & \\
\hline $22 / 20 / 17$ & 11 & \\
\hline $23 / 21 / 18$ & 12 & \\
\hline
\end{tabular}

In the table 4.4, under ISO codes, the three values separated by slashes represent the ISO code for impurities of the size $4 \mu \mathrm{m}, 6 \mu \mathrm{m}$ and $10 \mu \mathrm{m}$.

\section{PARTICLE COUNTERS}

A particle counter is an instrument that detects and counts particles. By its very nature a particle counter is a single particle counter, meaning it detects and counts particles one at a time. The nature of particle counting is based upon either light scattering, light obscuration, or direct imaging. A high intensity light source is used to illuminate the particle as it passes through the detection chamber. The particle passes through the light source (typically a laser or halogen light) and if light scattering is used, then the redirected light is detected by a photo detector. If direct imaging is used, a halogen light illuminates particles from the back within a cell while a high definition, high magnification camera records passing particles. Recorded video is then analysed by computer software to measure particle attributes. If light blocking (obscuration) is used the loss of light is detected.

\section{Liquid Particle Counters}

Liquid particle counters are used to determine the quality of the liquid passing through them. The size and number of particles can determine if the liquid is clean enough to be used for the designed application. Liquid particle counters are also used to determine the cleanliness level of hydraulic fluids, the reason being that $75-80 \%$ of hydraulic breakdowns can be attributed to contamination. There are various types, installed on the equipment, or portable units that can be transported to site, e.g., a construction site, and then used on the machine, e.g., a bulldozer, to determine fluid cleanliness. By determining and monitoring these levels, and following a proactive or predictive maintenance program, the user can reduce hydraulic failures, increase uptime and machine availability, and to reduce oil consumption. They can also be used to assure that hydraulic fluids have been cleaned using filtration, to acceptable or target cleanliness levels. There are various standards in use in the hydraulic industry, of which ISO 4406:1999, NAS 1638 and SAE AS 4059 are probably the most common.

\section{Particle counting - Operating principle}

The liquid that should be analysed flows through a measuring cell. Every particle goes through the volume that is illuminated with light as shown in figure 5.1. 
Consequently, no statistical approximation has to be done and knowledge about how the particles flow through the measuring cell is not necessary. If a particle is in the cell, the light intensity at the detector decreases depending on the diameter of the particle. The signal at the detector is converted and amplified. So every particle is analysed and the number of particles and the diameter is detected.

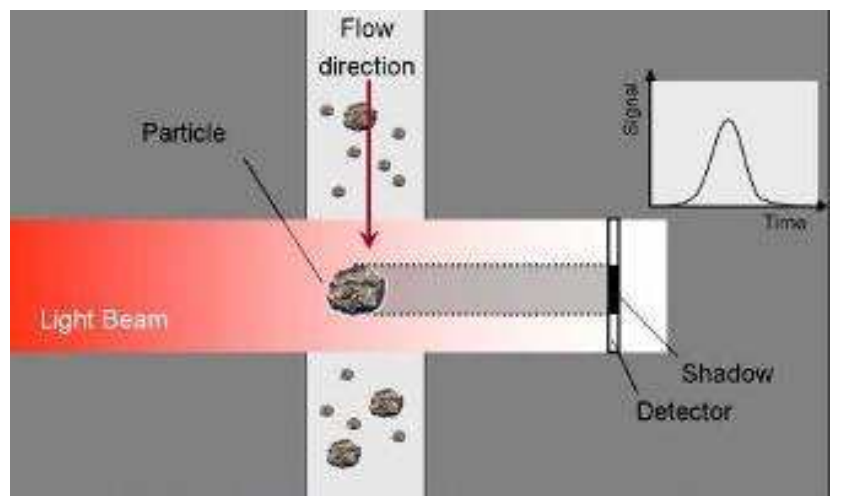

Figure 5.1 Operating principle of light extinction sensor

\section{Detection Method}

There are several methods used for detecting and measuring particle size or size distribution light blocking (obscuration), light scattering, Coulter principle and direct imaging. The light blocking optical particle counter method is typical useful for detecting and sizing particles greater than 1 micrometre in size and is based upon the amount of light a particle blocks when passing through the detection area of the particle counter. This type of technique allows high resolution and reliable measurement.

The light scattering method is capable of detecting smaller sizing particles. This technique is based upon the amount of light that is redirected by a particle passing through the detection area of the particle counter. This redirection is called light scattering. Typical detection sensitivity of the light scattering method is 0.05 micrometre or larger. However, employment of the condensation nuclei counter (CNC) technique would allow a higher detection sensitivity in particle sizes down to nanometre range. A typical application is monitoring of ultrapure water in semiconductor fabrication facilities.

The light blocking method is specified for particle counters that are used for counting in hydraulic and lubricating fluids. Particle counters are used here to measure contamination of hydraulic oil, and therefore allow the user to maintain their hydraulic system, reduce breakdowns, schedule maintenance during no or slow work periods, monitor filter performance, etc. Particle counters used for this purpose typically use ISO Standard 4406:1999 as their reporting standard, and ISO 11171 as the calibration standard. Others also in use are NAS 1638 and its successor SAE AS4059D.

Direct imaging is a technique that uses the light emitted by a laser as a source to illuminate a cell where particle are passing through. The technique does not measures the light blocked by the particles but rather measures the area of the particles functioning like an automated microscope. A pulsed laser diode freezes the particle motion. The light transmitted through the fluid is imaged onto an electronic camera with macro focusing optics. The particles in the sample will block the light and the resulting silhouettes will be imaged onto the digital camera chip.
There are two systems of measuring contamination values. One is called "On-line" and another is called "Off-line". In "On-line" measurement system NAS value is measured in operation site during filtration process is going on. On the other hand, in "Off-line" filtration system a sample is collected from the system and taken to the laboratory in a sample bottle and tested. Off-line is more erotic than On-line measurement because the probability of particle contamination is high in Off-line as particles may come from sample bottle or containers.

\subsection{HIAC ROC Online Counter}

HIAC ROC remote particle counters are constructed for harsh environments. The HIAC ROC excels in high pressure and high temperature applications and offers carefree maintenance. Serving a wide range of oil analysis and mobile applications, multi-point system monitoring as well as pointof-use applications.

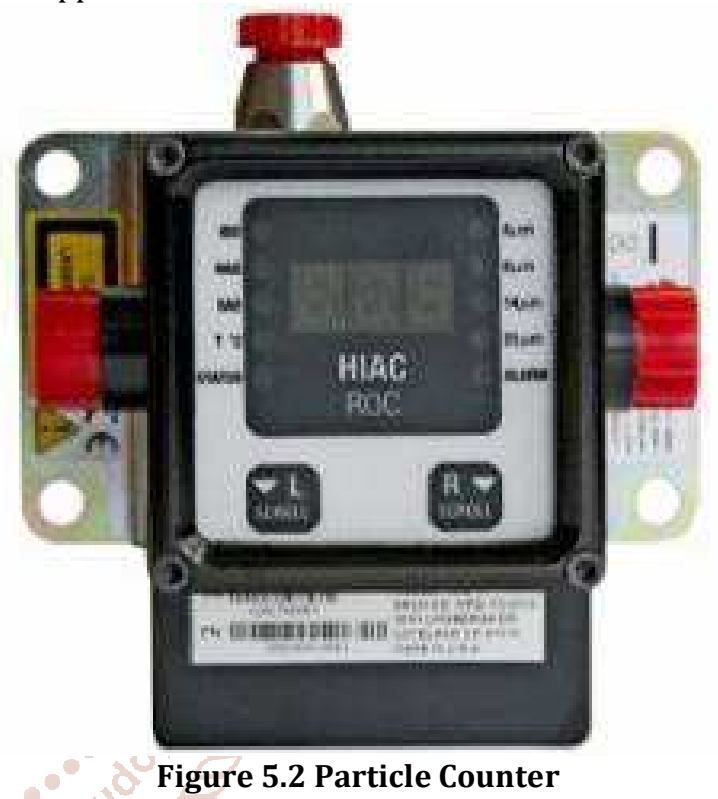

Specifications of On-Line Particle Counter Used

Manufacturer - Beckman Coulter

Model - HIAC ROC

Table 5.1 Particle Counter Specification

\begin{tabular}{|c|c|}
\hline Light Source & Laser diode \\
\hline Sizes & $4,6,14$, and $21 \mu \mathrm{m}$ (ISO) \\
\hline Display & $\begin{array}{c}\text { Optional local display presents ISO } \\
\text { codes, NAS or SAE codes, alarms, fluid } \\
\text { temperature and status }\end{array}$ \\
\hline Power & $\begin{array}{c}9 \text { to } 33 \mathrm{~V} \text { DC, } 150 \text { mA (power must be } \\
\text { supplied to instrument for operation) }\end{array}$ \\
\hline Output & $\begin{array}{c}\text { Display cable ports, alarms, local and } \\
\text { remote displays }\end{array}$ \\
\hline Reports & $\begin{array}{c}\text { ISO } 4406 \text { and codes for } 4,6,14,21 \mu \mathrm{m} \\
\text { (ISO), particles } / \mathrm{mL}\end{array}$ \\
\hline $\begin{array}{c}\text { Sensor Flow } \\
\text { Rate }\end{array}$ & $\begin{array}{r}50 \text { to } 500 \text { mL/min }(0.01 \text { to } 0.1 \\
\text { gal/min) through view area }\end{array}$ \\
\hline $\begin{array}{c}\text { Fluid } \\
\text { Compatibility }\end{array}$ & $\begin{array}{r}\text { Hydraulic and lubrication oils, } \\
\text { mineral, synthetic oils. }\end{array}$ \\
\hline Environment & $\begin{array}{c}\text { Operating Temperature }-10 \text { to } 60^{\circ} \mathrm{C}(- \\
14 \text { to } 140^{\circ} \mathrm{F} \text { ) }\end{array}$ \\
\hline $\begin{array}{c}\text { Sample } \\
\text { Pressure }\end{array}$ & Upto 500 bar \\
\hline
\end{tabular}




\section{PROBLEM DESCRIPTION}

\subsection{Definition of the Problem}

Hydraulics plays a vital role in industries due its versatility and ease of operation. Moreover, continuous research and development is paving way to exploring its use in various industries. Chettinad International Coal Terminal Private Limited focuses on using hydraulic wagons for the transit of coal due to the advantages it provides over other conventional counterparts. The working fluid in these wagons is prone to contamination which is inevitable. Contamination is inherently present in hydraulic fluids, even in unused oils, can only be controlled and not completely eliminated. The main problem posed by such inherent contaminants is wear of the parts which results in the parts becoming futile. At Chettinad coal terminal, this posed a serious threat that required renewing the parts within a short period of usage. The wearing tendency of the contaminants was better understood by studying the various types of contaminants. It was understood that the size of the contaminants plays a major role in wear, they tend to clog the orifices and cause jams. Further analysis lead to the conclusion that an additional filtration unit in addition to the primary filtration unit was essential. A secondary filtration unit placed externally would prove be effective in reducing the contamination to significant and safe limits.

\subsection{Objective of the project}

This project aims at discovering additional methods to reduce the level of contamination in hydraulic fluids. The safety limits for hydraulic fluids are defined by the National Aerospace Standards (NAS). The secondary filtration unit is placed externally and acts as an additional unit, separate from the inbuilt primary unit. This additional unit is designed to be a closed loop hence the vulnerability to contamination is further reduced. The external unit consists of multiple filters working independently so that a continuous operation can be achieved. The filters in the unit are of varying sizes so a wide range of contaminants can be filtered out making the fluid safer. The unit also consists of particle counters that are used to monitor the quantity of the contaminants. Thus the level of contamination, the size of the contaminants and their quantity can be measured and reduced to safe limits within a short duration of time. Moreover, the fluid once filtered remains safe and can be used without any further processing for a significantly long duration.

\subsection{Hydraulic Drive System used at the Company}

The drive system consists of a tank, a primary filter, axial piston pumps, manifolds and axial piston motors. The hydraulic fluid is stored in the tank which has a capacity of 800 litres, it is sent to the primary filtration unit. Primary filtration unit is inbuilt and always present as a part of the drive system and it has a filter of fineness $10 \mu \mathrm{m}$. These components excluding the primary filter and tank form the "charge circuit". Charge circuit alone can occupy oil of volume 150litres. After the hydraulic fluid has gone through a filter it is pumped into the motors by axial piston motors to 400bar of pressure which is required to move the wagon initially. The manifold unit is present in between the pumps and motors. The purpose of the manifold is to branch out the fluid coming in through the pumps. The axial piston motors are coupled to the wagon's wheels hence the hydraulic fluid running the motors in turn runs the wheels, hence the locomotive gets the power to run. The hydraulic fluid coming out of the motors still have a pressure of $30 \mathrm{bar}$, pass through another manifold unit and are returned to the pumps. Thus, the hydraulic fluid is circulated throughout the drive system in the same sequence until the operation is manually stopped. The hydraulic fluid passes through the primary filter only once during the entire operation time and is circulated within the charge circuit for the remaining period of operation. The cleanliness of the oil can't be accurately maintained with this arrangement as the fluid flows through the filter only once and is prone to induced contamination caused by wear of parts during operation. The circuit of the hydraulic drive is shown in the Figure 6.1.

\section{CHARGE CARCUI}

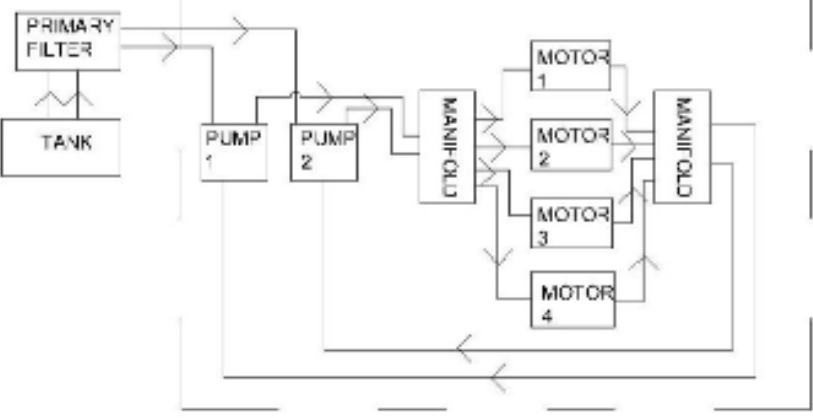

Figure 6.1 Hydraulic Drive System

6.4 Closed Loop Filtration as Solution

In order to reduce the contamination level in the charge circuit, we are introducing a very effective way of ensuring thorough fluid conditioning with a dedicated off-line circulation loop, or "kidney" loop or Closed loop filtration. This system uses a separate circulation pump that runs continuously, circulating and filtering the fluid. The outlets from the motor containing oil at a pressure of 30bar are connected to a manifold, which is further connected to the external filtration unit. The filtered oil is sent to a manifold which is connected to pumps. Oil taken from the charge circuit is again sent back to it, thus a closed loop filtration is achieved. The hydraulic drive when attached to the filtration unit is shown in figure 6.2 .

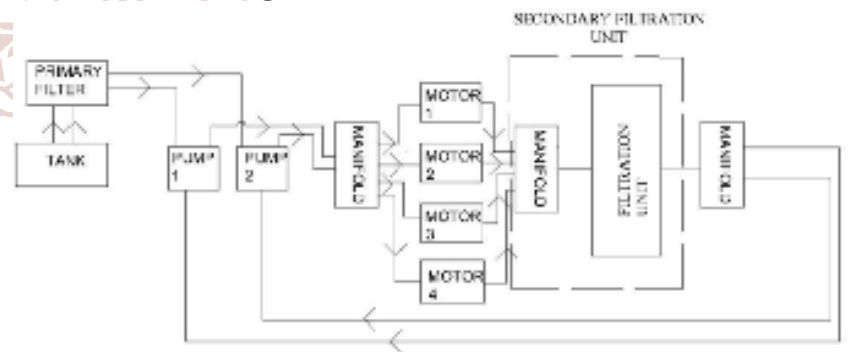

Figure 6.2 Hydraulic Drive with External Filtration unit

\section{LITERATURE REVIEW}

\subsection{Review on Oil Contamination and its Filtration}

C.C.S. Le Clair (1997) has explained that getting the requisite amount of oil through the filter element is facilitated if a sharp circulation over the filter surface can be maintained and is further facilitated if the temperature of the oil can be raised even though it may be only locally and not immediately throughout the whole system.

Eric Springston (1994) claims a breather cap for an oil reservoir, said breather cap being positioned over an oil reservoir outlet having the shape of a cylindrical bore, said breather cap receiving high-velocity air containing suspended droplets of oil, said breather cap separating the oil from said air, which is then vented to the atmosphere. 
Hydraulic reservoir with a breather cap facilitates its venting.

George Clough (1994) designed an Industrial filtration apparatus for the separation of solids entrained in a fluid stream comprising a flexible perforate filtering sleeve closed at one end such that fluid can pass through perforations in the sleeve but entrained solids of a predetermined size are retained within the closed end of the sleeve.

James Snyder (1991) has described a new method to reduce the contamination of lubricating oil in gas turbines. In pressurized lubrication systems, a lubricant flow is directed through a network of conduits to specifed regions of a machine to serve numerous functions, such as lubrication and cooling. This lubricant flow may carry a residual quantity of particulate matter, such as metallic filings, sediments, or other undesirable solids generated by, for example, the material wear occurring at sliding or impacting surfaces of numerous internal components.

Josef Thoma (2001) has presented a new device for counting suspended particles in liquids and more particularly to devices for counting particulate contaminants in oil.

Joseph Marino (1998) has identified a method for determining the contamination of a fluid system having a fluid reservoir at one end of the system and suction pump at the other end. A filter element is selected having a dirt holding capacity equal to the maximum acceptable limit of the system and placed between the pump and reservoir. The fluid is then drawn through the filter at a predetermined rate and the differential pressure produced across the filter element is recorded and indicated as the contamination level of the system.

Kim Hodgson (1998) has explained a system for determining the level of particulate contaminants in a fluid utilizes a porous filtration element having filtration pores in fluid series with a volume indicator. The filtration medium is provided with filtration pores which have a generally predetermined size such that oversized particles of the particulate contaminants are accumulated on one side of the filter medium.

M. Singh (2011) in his work has proved that Oil contamination is the major source of failure and wear of hydraulic system components. As per his literature survey, approximately $70 \%$ of hydraulic system failures are caused by oil contamination. Hence, to operate the hydraulic system reliably, the hydraulic oil should be of perfect condition. This requires a proper 'Contamination Management System' which involves monitoring of various parameters like oil viscosity, oil temperature, contamination level etc. It is observed that by proper monitoring of contamination level, there is considerably increase in reliability, economy in operation and long service life. This also prevents the frequent failure of hydraulic system.

Verdegan B. (2001) has said that wear rates are related to the contaminant size distribution in the oil and degree of filtration. For engine protection the author has said that the size and concentration of oil contaminants are as important as their chemical composition.

W. Schneider (2005) has found that the range in the measured filtration efficiencies decreases quite markedly with finer porosity of filter system i.e. the reliability of the filtration system increases as we move to finer pore filters.

\section{SECONDARY FILTRATION UNIT}

As we discussed earlier, to overcome the problem of wear due to contamination a secondary closed loop filtration unit was designed and its circuits are explained. The fabricated unit is stored in safe environment and brought near the locomotive with help of cranes and trained personals during the time of filtration.

\subsection{Filter Element}

The filter element is the central part of industrial filters. The actual filtration process takes part in the filter element. The applied filter elements and the filter media used in the filter elements determine the major filter characteristics such as retention capacity, contamination retention and pressure loss. Filter elements consist of a combination of radially pleated filter media which are laid around a perforated supporting tube. The filter element is vertically sealed by means of an adhesive. A perforated protective cage is laid around the filter mat. Supporting tube and filter mat are glued to both end discs. The protective cage allows for a continuous fluid flow around the filter mat and, at the same time, provides mechanical protection against external damage. Seal rings are provided between the filter element and the filter housing as a sealing.

A filter medium is any material that, under the operating conditions of the filter, is permeable to one or more components of a mixture, solution or suspension, and is impermeable to the remaining components.

Depending on the application and requirements, different filter media in different filtration ratings are used for the separation of particles. Various Filter media are listed in the table 8.1 and their electron microscope images are shown in figures $8.1(\mathrm{a})$ to $8.1(\mathrm{e})$.

Table 8.1 various filter media and their Applications

\begin{tabular}{|l|l|l|}
\hline \multicolumn{1}{|c|}{ Filter medium } & Filter rating & \multicolumn{1}{|c|}{ Application } \\
\hline $\begin{array}{l}\text { Micro Glass } \\
\text { Depth filter, combination of inorganic micro glass filter } \\
\text { medium. }\end{array}$ & 1 to $20 \mu \mathrm{m}$ & $\begin{array}{l}\text { For highest pureness demands in hydraulic } \\
\text { fluids and lubricants. }\end{array}$ \\
\hline $\begin{array}{l}\text { Filter Paper } \\
\text { Inexpensive depth filter made of filter paper with } \\
\text { supporting tissue. }\end{array}$ & 10 to $25 \mu \mathrm{m}$. & For coarse filtration and pre-filtration. \\
\hline $\begin{array}{l}\text { Metal Fibre Fabric Material } \\
\text { Depth filter made of stainless steel fibres with } \\
\text { supporting mesh. }\end{array}$ & 25 to $60 \mu \mathrm{m}$ & $\begin{array}{l}\text { For highest cleanliness requirements for } \\
\text { aggressive industrial and chemical fluids } \\
\text { subjected to high operating temperatures. }\end{array}$ \\
\hline $\begin{array}{l}\text { Fleece Material } \\
\text { Surface filter made of extremely solid fibre composite. }\end{array}$ & $\begin{array}{l}\text { Surface, coarse and pre-filtration, in particular } \\
\text { recommended for cooling lubricants. }\end{array}$ \\
\hline $\begin{array}{l}\text { Water-absorbing } \\
\text { Depth filter, fleece material with water-absorbing } \\
\text { material, combined with micro glass filter media. }\end{array}$ & $\begin{array}{l}\text { Dehumidification of hydraulic oil, lubricating } \\
\text { oil and air. }\end{array}$ \\
\hline
\end{tabular}




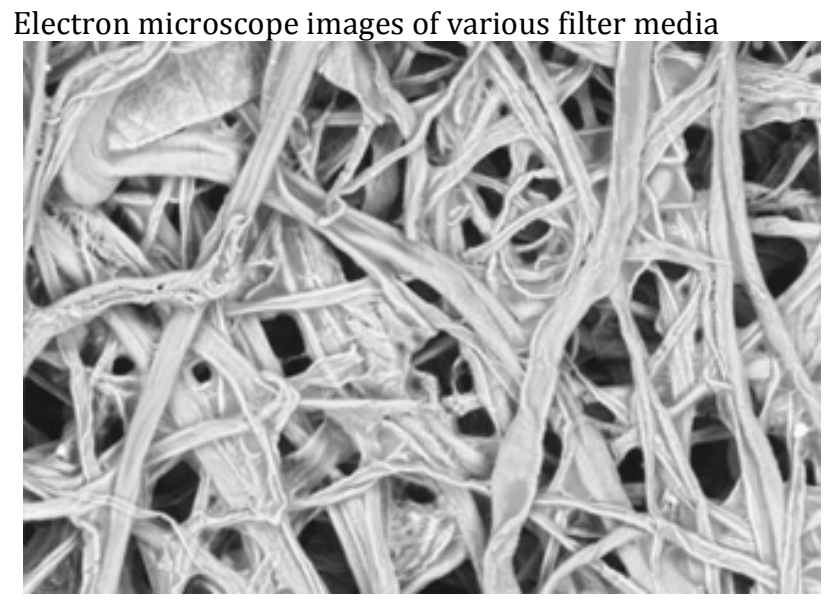

Fig7.1 (a) Fabric Medium

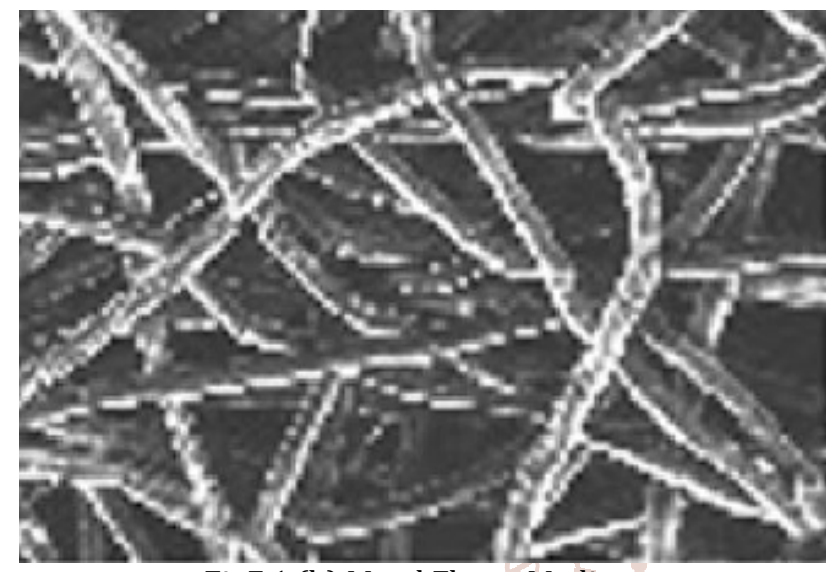

Fig7.1 (b) Metal Fleece Medium

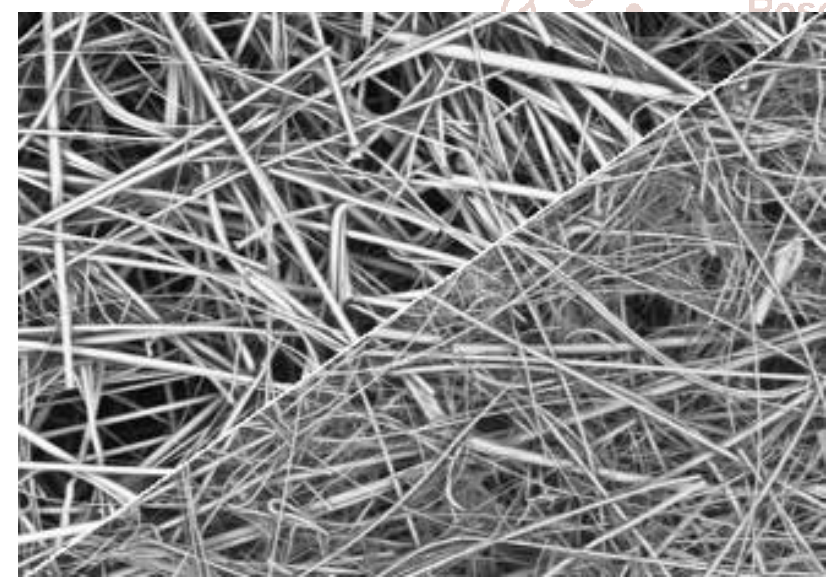

Fig7.1 (c) Micro glass Medium

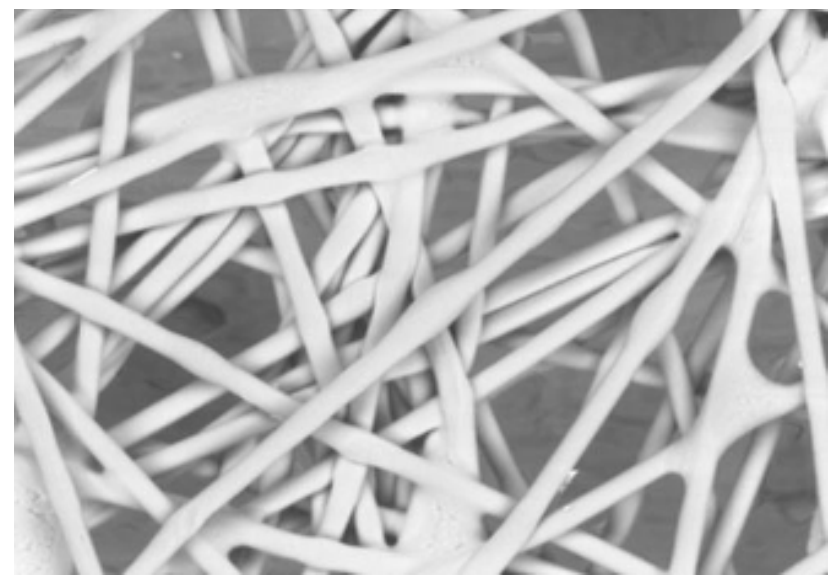

Fig7.1 (d) Polypropylene Medium

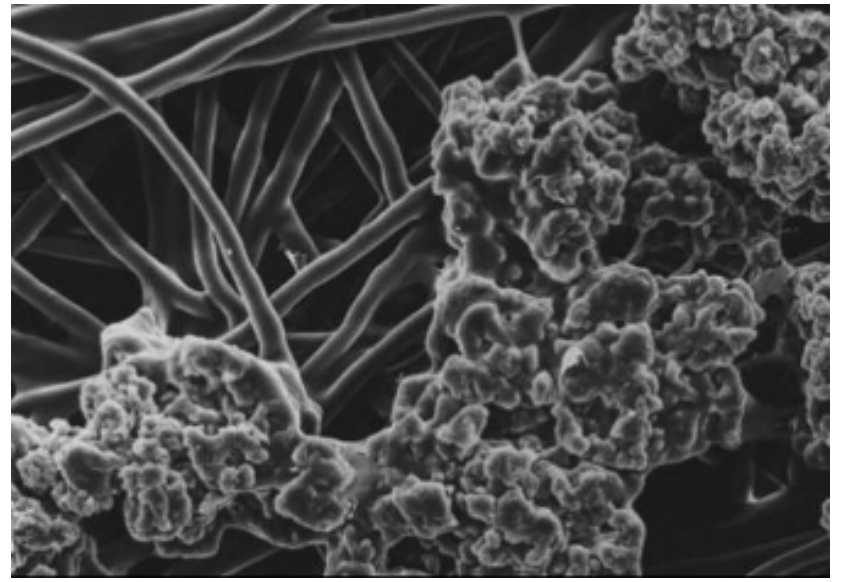

Fig7.1 (e) Water Absorbing Medium

\subsubsection{Filter medium employed in the unit}

A filter medium should be strong (in tension at least), flexible, resistant to corrosion and abrasion, easily manipulated into the required shapes and capable of being made with a range of porosities. The filter medium which is been selected in the filtration unit is Fabric material. Fabrics can be considered as a direct, and physically stronger, alternative to papers and are employed in a similar manner for pleated elements, etc. Fabric elements were originally the most commonly used type of filter medium for fine filtration and are generally comparable with modern paper media as regards to the performance achievable. Until the appearance of treated paper elements, they were regarded as a superior type, although the two are now strictly competitive for similar duties. Treated papers are now the more common because of lower cost, but fabric elements are capable of withstanding higher working pressures with similar geometry. However, fabric elements have a lower specific resistance than paper elements and, being thicker, can also carry a heavier load of contaminant per unit area. This latter advantage is normally offset by the fact that, for the same over- all size, the surface area of the fabric element is reduced because of its greater thickness.

\subsubsection{Perforated plate}

Perforated metal sheets are more rigid and can be made stronger than woven wire cloths and so they find particular applications in strainers, coarse filters and screens. Perforated metal strainers have a predictable and consistent performance because the size of the screen openings is controlled in the manufacturing process and is set to have very fine pores. Stainless steel is preferred for perforated plate material in the filtration unit as it is corrosion resistant.

\subsection{Circuitry \\ 8.2.1 Circuit Description}

Table 8.2 Circuit Description

\begin{tabular}{|c|c|}
\hline Motor & Power - 5HP \\
\hline Pump & Diaphragm pump \\
\hline 3 Way Ball valve & Manually operated valves \\
\hline Filter 1 & $12 \mu \mathrm{m}$ \\
\hline Filter 2 & $5 \mu \mathrm{m}$ \\
\hline Particle Counter & HIAC ROC on-line \\
\hline
\end{tabular}

\subsubsection{Secondary filtration unit when it is not in use}

The secondary filtration unit consists of motors, valves, filters and particle counters as shown in figure8.2. The hydraulic oil can be allowed to flow through one of the two 
input valves depending on the pressure of the fluid. Unpressurized fluid is pumped in via the input valve 1 and the fluid that is being circulated within the circuit enters the filtration unit via input valve 2 . The filtration unit consists of a set of two filters, one of 12 micron size and the other of 5 micron size. The fluid flowing in is allowed to flow through one filter at once and the process can be repeated to allow the flow through the other filter. Filtration

using both the filters simultaneously is not possible. The fluid after passing through the filter is directing towards a particle counter where the quantity of contamination is determined. This is used to closely monitor the amount of contamination in the given working fluid. From the particle counter the fluid is sent via the output valve to continue with the required operation. A pressure relief valve is placed near the pump to monitor the pressure rise in the unit. In order to ensure unidirectional flow of the working fluid, a set of flow control valves are placed in position. This set up proves to be a compact and highly efficient to reduce and maintain safe levels of contamination.

\subsubsection{When the unit is connected to locomotive (Closed loop filtration)}

The drive system with the primary or the inbuilt filtration unit cannot prevent the hydraulic fluid from contamination due to internal factors this leads to wear of the components and in worst cases would require changing of components. Changing the components frequently is time consuming and not economical. Thus, the need for a secondary filtration unit arises. This secondary unit is externally placed and is positioned such that the hydraulic fluid passed through this secondary unit during very cycle of the operation as shown in figure8.3. The hydraulic fluid flowing out of the motors after completion of the operation is directed towards the external filter instead of the pump as it is conventionally.
From the motors the fluid passes through the secondary filtration unit from where it is allowed to flow to the pumps and the cycle of operation continues. The secondary filtration unit remains active throughout the operation process and the fluid passes through the filter during every cycle of operation. Thus unlike in the conventional case where the fluid is left unmonitored once the operation cycle starts, the fluid's contamination level is strictly monitored and the contamination levels are maintained within safe limits throughout the operation.

\subsubsection{When the unit is working in a circuit to fill a tank:}

The working of the circuit is similar to when it is used in a locomotive. The only difference is that the incoming fluid is unpressurised. The tank containing the fluid to be filtered is connected via the inlet valve 1 where a pump is a tank from used to draw the fluid inside the circuit under pressure as shown in figure 8.4. The pressure relief valve is placed across the pump motor set up to maintain a safe working pressure within the circuit. The fluid pumped in flows through the each of the filters as desired and then through the particle counter. After completing the filtration process, the fluid is stored in an external oil utility tank.

\subsubsection{Normal flushing mode}

The working of the circuit is similar to filling filtered oil to tank process. The external oil tank containing the fluid to be filtered is connected via the inlet valve 1 where a pump is used to draw the fluid inside the circuit under pressure as shown in figure 8.5. The pressure relief valve is placed across the pump motor set up to maintain a safe working pressure within the circuit. The fluid pumped in flows through the each of the filters as desired and then through the particle counter. After completing the filtration process, the fluid is stored in an external oil utility tank.

The following circuit explains the unit when it is not in use:

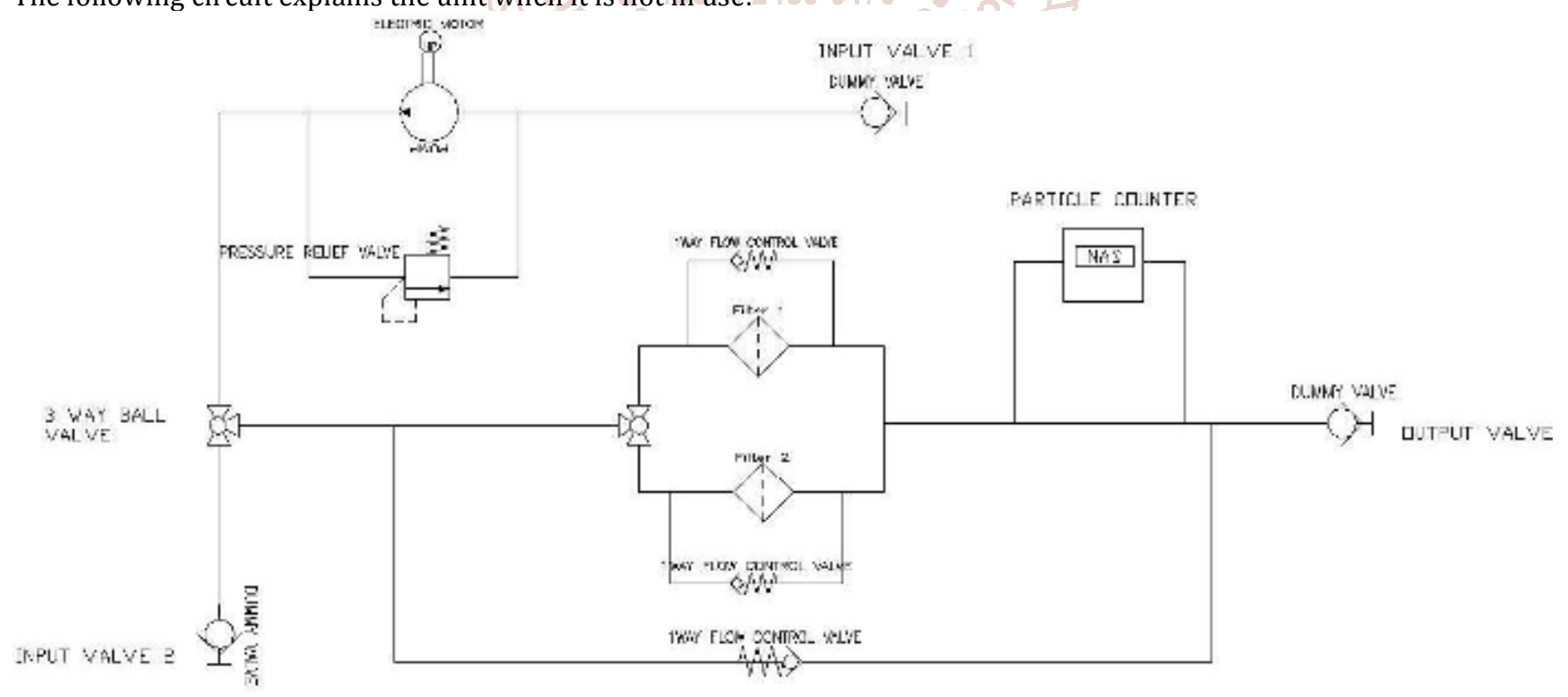

Figure 8.2 Secondary Filtration Unit Circuit 
International Journal of Trend in Scientific Research and Development (IJTSRD) @ www.ijtsrd.com eISSN: 2456-6470 When the unit is connected to a locomotive (Closed loop filtration):

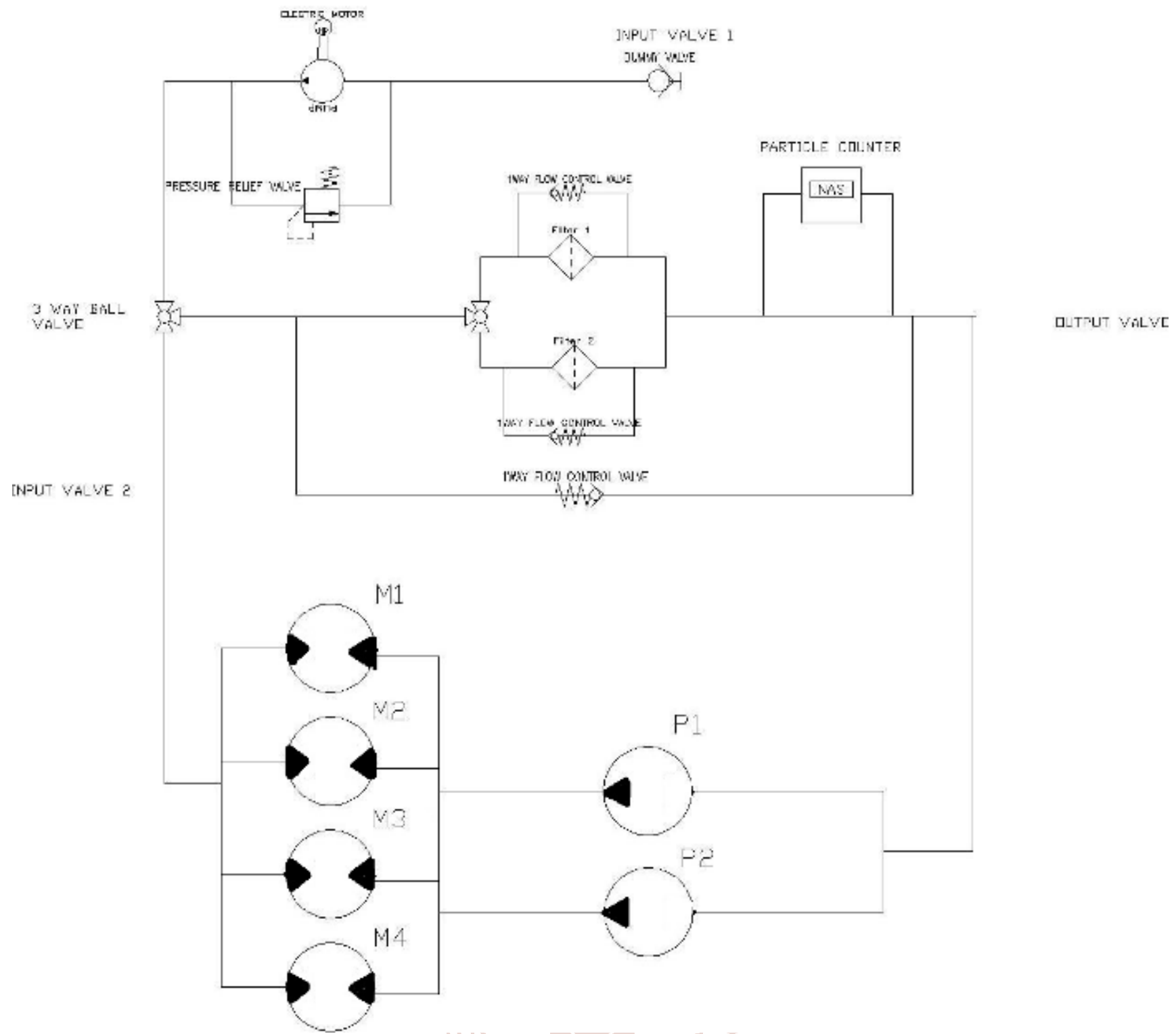

Figure 8.3 Filtration Unit when Connected to Closed Loop

When the unit is wor king in a circuit to fill a tank:

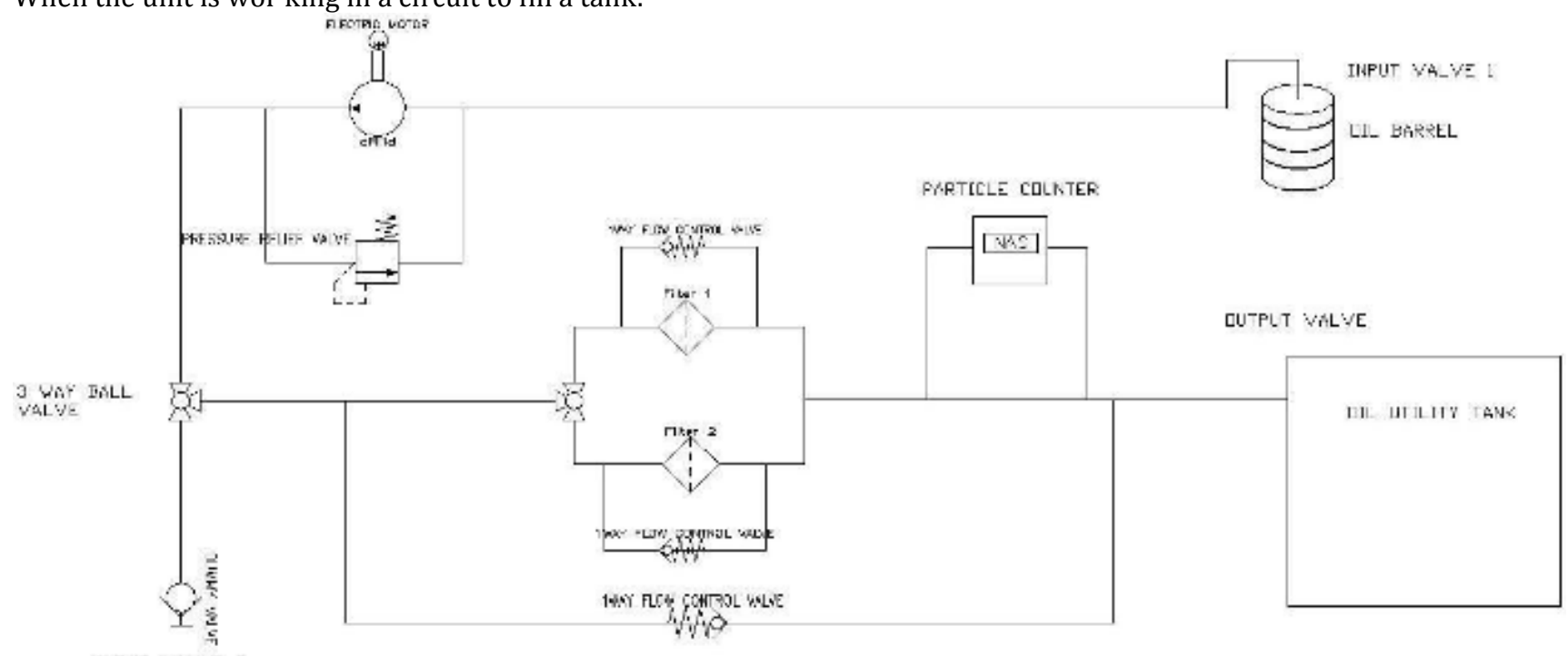
IRPJT VALVE E

Figure 8.4 Filtration Unit when filling a Tank 
The next circuit depicts the unit during a normal flushing mode:

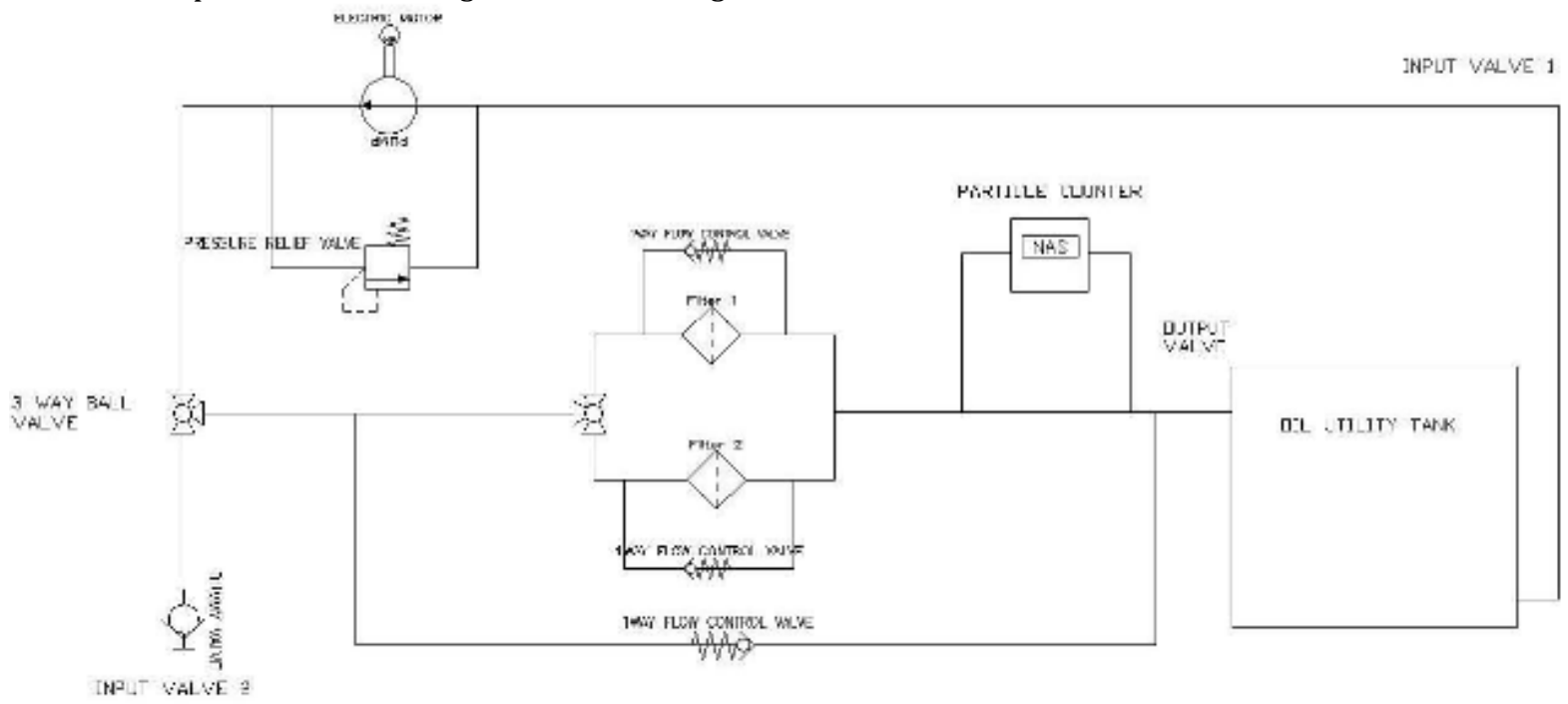

Figure 8.5 Filtration Circuit during regular flushing

The hydraulic symbols used in the circuits are explained in the table 8.3.

Table 8.3 Hydraulic Symbols Used in Circuit

\begin{tabular}{|c|c|c|c|c|c|}
\hline S.No. & Symbol & Description & S.No. & Symbol & Description \\
\hline 1. & & $\begin{array}{l}\text { Pressure } \\
\text { relief valve }\end{array}$ & 5. & & $\begin{array}{c}\text { Check valve } \\
\text { (Dummy } \\
\text { valve) }\end{array}$ \\
\hline 2. & & $\begin{array}{c}\text { Uni- } \\
\text { Directional } \\
\text { Pump }\end{array}$ & 6. & & Filter \\
\hline 3. & & $\begin{array}{c}\text { Spring } \\
\text { controlled } \\
\text { one way } \\
\text { Flow control } \\
\text { valve }\end{array}$ & 7. & & $\begin{array}{c}\text { Bi- } \\
\text { directional } \\
\text { motor }\end{array}$ \\
\hline 4. & & $\begin{array}{c}\text { Bi- } \\
\text { directional } \\
\text { pump }\end{array}$ & 8. & & $\begin{array}{c}3 \text { Way ball } \\
\text { valve }\end{array}$ \\
\hline
\end{tabular}

The filtration unit which was fabricated is shown in the figure 8.6 to 8.10. 


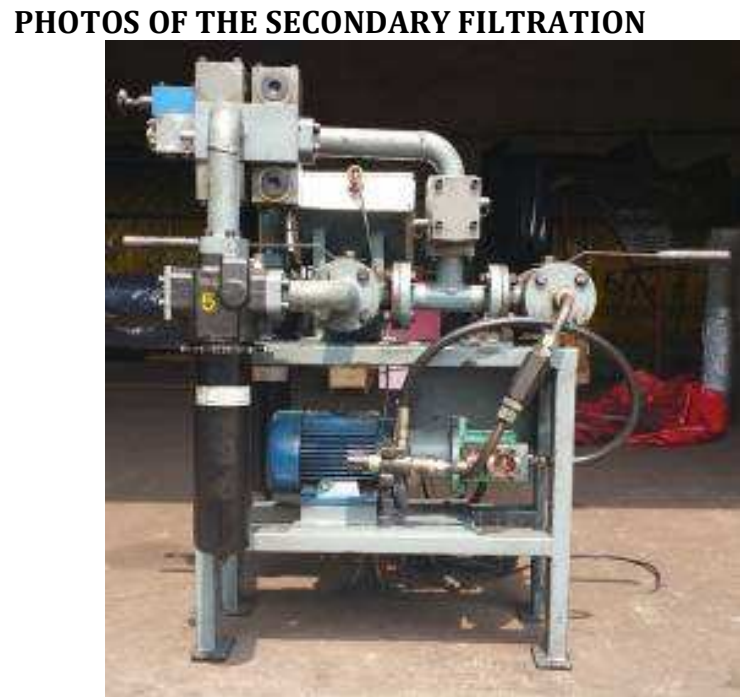

Figure 8.6 Filtration unit (Front)

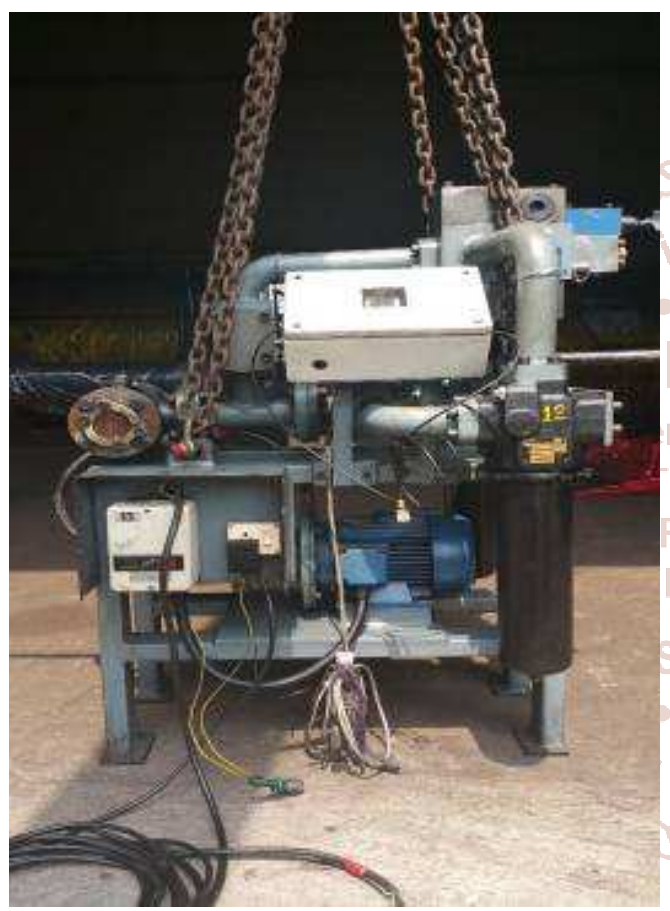

Figure 8.7 Filtration unit (Rear)
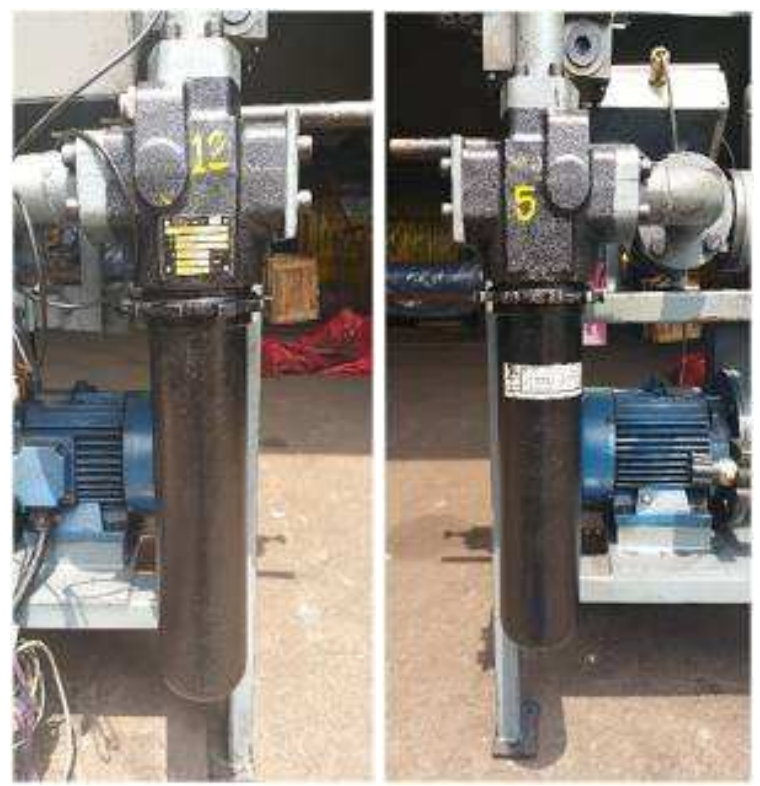
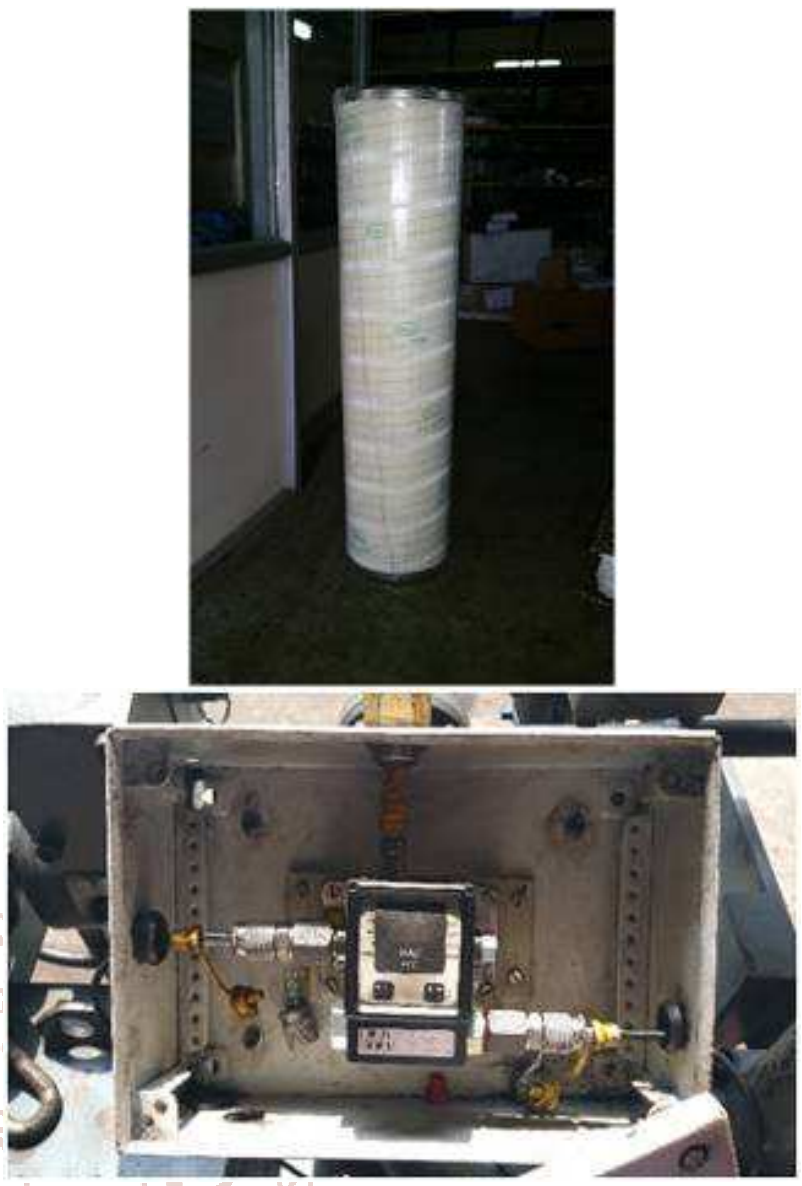

Figure 8.8 micron and 12 micron Filters in unit and particle counter in the unit (fig 8.10)

\section{RESULTS AND DISCUSSIONS}

In order to reduce the particulate contamination in hydraulic oil being used in the charge circuit of the hydraulic drive system of the locomotive, a closed loop external filtration unit was designed and manufactured. It was connected to the outlet of the oil tank and tested for open loop filtration and also connected to charge circuit and tested for closed loop filtration. The result of the filtration operation and the change in contamination levels are explained.

\subsection{Observation}

\subsubsection{Open Loop Filtration Results}

The filtration setup was used to reduce the contamination of oil to recommended level before filling it to tank. The readings were tabulated and shown in Table 9.1

Table 9.1 Open loop Filtration Outcomes

\begin{tabular}{|c|c|c|c|c|c|c|}
\hline \multirow[b]{2}{*}{$\begin{array}{c}\text { S. } \\
\text { no }\end{array}$} & \multirow[b]{2}{*}{$\begin{array}{c}\text { Impurity } \\
\text { Level }\end{array}$} & \multicolumn{3}{|c|}{ ISO Code } & \multirow[b]{2}{*}{$\begin{array}{l}\text { Time } \\
\text { taken }\end{array}$} & \multirow{2}{*}{$\begin{array}{c}\text { Tempe } \\
\text { rapture } \\
\left({ }^{0} \mathrm{c}\right)\end{array}$} \\
\hline & & $\begin{array}{c}4 \\
\text { um }\end{array}$ & $\begin{array}{c}6 \\
\mu m\end{array}$ & $\begin{array}{l}14 \\
\mu \mathrm{m}\end{array}$ & & \\
\hline \multirow{2}{*}{1.} & $\begin{array}{c}\text { Initial } \\
\text { Impurity } \\
\text { Level }\end{array}$ & 19.2 & 9.2 & 8.1 & \multirow{2}{*}{$\begin{array}{l}\text { 4hrs } \\
45 \mathrm{~min}\end{array}$} & 34.0 \\
\hline & $\begin{array}{c}\text { Final } \\
\text { Impurity } \\
\text { Level }\end{array}$ & 15.1 & 0.0 & 0.0 & & 38.3 \\
\hline
\end{tabular}

The Table 9.1 shows the statistics indicated by On-line particle counter installed in series to the filter collected during the start and end of the filtration process. It clearly shows the change in impurity levels at their respective sizes. A slight increase in temperature is noted which is within the safe limit. 


\subsubsection{Closed Loop Filtration Results}

The filtration unit was connected to the charge circuit of the locomotive and the filtration process was carried out. The readings were tabulated and shown in Table 9.2

Table 9.2 Closed Loop filtration Outcomes

\begin{tabular}{|c|c|c|c|c|c|c|}
\hline \multirow{2}{*}{$\begin{array}{l}\text { S. } \\
\text { no }\end{array}$} & \multirow{2}{*}{$\begin{array}{c}\text { Impurity } \\
\text { level }\end{array}$} & \multicolumn{3}{|c|}{ ISO Code } & \multirow{2}{*}{$\begin{array}{l}\text { Time } \\
\text { Taken }\end{array}$} & \multirow{2}{*}{$\begin{array}{c}\text { Temper } \\
\text { ature } \\
\left({ }^{\circ} \mathrm{c}\right)\end{array}$} \\
\hline & & $\begin{array}{r}4 \\
\mu \mathrm{m} \\
\end{array}$ & $\begin{array}{c}6 \\
\mu \mathrm{m}\end{array}$ & $\begin{array}{r}14 \\
\mu m \\
\end{array}$ & & \\
\hline \multirow{2}{*}{1.} & $\begin{array}{c}\text { Initial } \\
\text { Impurity } \\
\text { Level }\end{array}$ & 21 & 8 & 7 & \multirow{2}{*}{$\begin{array}{c}10 \mathrm{hrs} \\
30 \mathrm{~min}\end{array}$} & 36 \\
\hline & $\begin{array}{c}\text { Final } \\
\text { Impurity } \\
\text { Level }\end{array}$ & 16 & 0 & 0 & & 40.5 \\
\hline
\end{tabular}

The Table 9.2 shows the statistics indicated by On-line particle counter installed in series to the filter collected during the start and end of the filtration process. It clearly shows the change in impurity levels at their respective sizes. A slight increase in temperature is noted which is within the safe limit.

\subsection{Challenges Faced after Filtration}

Both open and closed loop filtration were carried out in the locomotive. The locomotive was back to operation. After certain hours of running the levels of contamination got increased. In order to bring back the recommended levels of contamination, filtration was carried out. The details of the locomotive oil cleanliness with respect to running time are shown in the table 9.2.

Table 9.3 Oil Cleanliness Value in the Locomotive

\begin{tabular}{|c|c|c|}
\hline Time in hours & NAS Value & ISO code \\
\hline 1 Hour & 19 & $29 / 29 / 19$ \\
\hline 10 Hours & 8 & $19 / 6 / 0$ \\
\hline 332 Hours & 11 & $22 / 10 / 8$ \\
\hline 500 Hours & 7 & $18 / 6 / 0$ \\
\hline
\end{tabular}

A graphical representation to depict the change in impurity level of the hydraulic fluid used during filtration and operation are explained in the figure 9.1

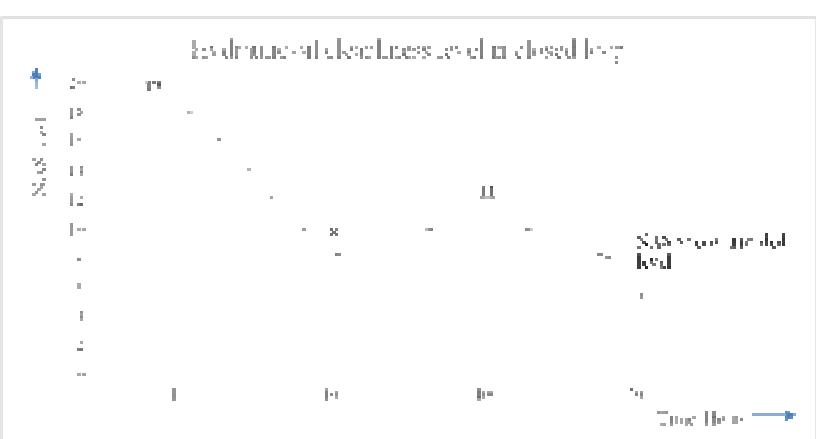

Figure 9.1 Closed Loop Filtration Outcomes

The graph in figure 9.1 is plotted between the NAS value (depicting the impurity level) on the y axis and the time along $\mathrm{x}$ axis.

The starting point of the curve represents start of the filtration operation. The contamination level is recorded in terms NAS values. Before the filtration operation, the level of contamination level is high, at 19 . After filtration using the closed loop filtration process for nearly ten hours, the level of contamination has reduced significantly to a safer limit. The NAS value 8 is the recommended safety limit. The filtration process is done whenever the impurity level is higher than safe limit, during operation of the locomotive the contamination levels rose again to NAS 11. The reason for the rise of contamination level during operation is due to the type of breather used. A breather is an air filtering device fit to the top of the oil tank, which helps in avoiding formation of vacuum inside the tank when the oil inside the tank gets used up. The locomotive uses a $10 \mu \mathrm{m}$ breather which is not sufficient. The locomotive requires another round of filtration after running for about four hundred hours. Thus, the next round of filtration is carried out. This again reduces the contamination level to NAS value of 7 , which is within safe limits thus making the fluid safe to use. In order to reduce the inlet of air borne contaminants $3 \mu \mathrm{m}$ breather is installed. The use of $3 \mu \mathrm{m}$ breather is believed to drastically reduce the entry of air borne particulate contaminants into the hydraulic oil tank.

\section{CONCLUSION}

From the experiment conducted, the results obtained are as follows,

D In open loop filtration process the contamination levels have been reduced accordingly:

- There was a $21.35 \%$ reduction in $4 \mu \mathrm{m}$ particles

- A $100 \%$ reduction was observed in both $6 \mu \mathrm{m}$ and $14 \mu \mathrm{m}$ particles in a duration of 5 hours.

$>$ In closed loop filtration process the contamination levels have been modified accordingly:

- There was a $23.81 \%$ reduction in $4 \mu \mathrm{m}$ particles

- cieth the $6 \mu \mathrm{m}$ and $14 \mu \mathrm{m}$ particles showed a $100 \%$ reduction in a duration of 11 hours.

Hence it can be concluded that the secondary filtration process is successful in reducing the particle contamination in working fluids.

\section{REFERENCES}

[1] A. A. Chesnokov, N. A. Antipina, O. N. Nikolskaya and A. I. Shachin (1984), "Filterability of oils for hydraulic systems in industrial equipment", Chemistry and Technology of fuels and oils, Vol. 20(8), pp. 383-386.

[2] A. L. Price and B. J. Roylance (1988), "Detection and diagnosis of wear through oil and wear debris analysis", Journal of Condition Monitoring, Vol. 1, pp. 377-419.

[3] D. R. Sperry (1996), "Oil Filtration”, Journal of Oil and Fat Industries, Volume 3(2), pp. 43-47.

[4] I. M. Sorotskin and I.I. Fishman (2001), "Trends in removable medium drum filter design", Journal of Chemical and Petroleum Engineering, Vol. 5(5), pp. 419423.

[5] M. Singh, G. S. Lathkar, and S. K. Basu (2012), "Failure Prevention of Hydraulic System Based on Oil Contamination", Journal of the Institution Engineers, Vol. 93(3), pp. 269-274.

[6] S. K. Basu, S. K. Sarkhel, S. K. Chakravorty (1992), "Oil analysis-a tool for condition monitoring of diesel engines", Vol. 3(2), pp. 47-55.

[7] Lawrence K. Wang, Clint Williford and Wei-Yin Chen (2004), "Fabric Filtration", Journal of Environmental Engineering, Vol. 1, pp. 59-95. 
[8] Martin Reik and Frank Oberli (2014), "Filter Design for Lubricating Oil and Hydraulic Systems", Journal of Lubricants and Lubrication, Vol. 1, pp. 569-588.

[9] Martin Reik and Frank Oberli (2014), "Filtration of Lubricating Oils and Hydraulic Fluids", Journal of Lubricants and Lubrication, Vol. 1, pp. 588-593.

[10] Martin Reik and Frank Oberli (2014), "Selection of Filters for Lubricating Oil and Hydraulic Systems", Journal of Lubricants and Lubrication, Vol. 1, pp. 17101720.

[11] Mohamed Rafik Sari, Ammar Haiahem and Louis Flamand (2007), "Effect of Lubricant Contamination on Gear Wear", Journal of Tribology, Vol. 27(1), pp. 119126.
[12] P.J. Heney (1998), "Effective filtration-breaking the chain reaction of wear", Hydraulics and Pneumatics, Vol. 51, pp. 43-52.

[13] Terence Allen (1990), "On-line particle size analysis", Journal of Particle size measurement, Vol. 1, pp. 682737.

[14] V.M. Kornev and A.G. Demeshkin (2014), "Model of stepwise propagation of the tip of a hydraulic fracture in the absence of filtration", Journal of applied mechanics and technical physics, Vol. 55(3), pp. 515523

[15] W.D. Williamson (1979), "Hydraulic component cleanliness testing method. 